\title{
Diagnosis: Orbital Compression Syndrome in Sickle Cell Disease
}

Editor: Husn Frayha

Author: Ahmad M. Al-Suleiman

$\mathrm{F}$ igure 1 shows the left eye proptosis. Figure 2 is a CT scan showing soft tissue opacity in the left orbit, with a density of 86 Hounsfield units, which is close to fresh blood density, and displacement of the left globe downward. Figure 3 is a peripheral blood film showing sickle cells, anisocytosis, and evidence of hyposplenism (target cells, Howell-Jolly bodies).

\section{Discussion}

Sickle cell disease is a genetic disorder of hemoglobin production characterized clinically by anemia, recurrent painful crisis, splenic and hepatic sequestration, acute chest syndrome, stroke and bacterial sepsis. Orbital involvement in sickle cell disease is rare. ${ }^{1,2,3}$ Only a few cases are reported from Saudi Arabia. ${ }^{4}$

The orbit is a concave-shaped space comprised of seven bones (frontal, greater and lesser wings of the sphenoid, zygoma, maxilla, lacrimal, palatine and ethmoid). ${ }^{5}$ Orbital swelling in sickle cell disease occurs with orbital bone infarction, cellulitis, orbital abscesses, and orbital compression syndrome. Orbital compression syndrome is characterized by frontal headache, eyelid edema, proptosis, and fever. ${ }^{3,6}$ The clinical presentation in our patient is compatible with the diagnosis of orbital compression syndrome. This syndrome is believed to be due to hematoma adjacent to the orbital bones and appears to result from bone marrow infarction. Bilateral involvement occurs in over half of the cases. ${ }^{6}$ Orbital compression syndrome ranges from mild, which can be resolved with conservative treatment to sight-threatening, which needs surgical exploration and evacuation of the hematoma to prevent loss of vision. ${ }^{7}$

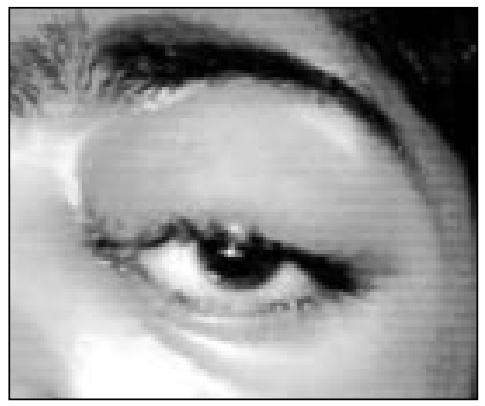

Figure 1.

Photograph of the left eye showing proptosis (downward and outward).

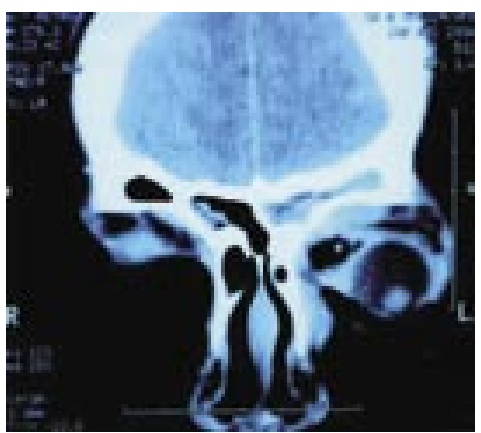

Figure 2. CT scan of the orbits of the eye.

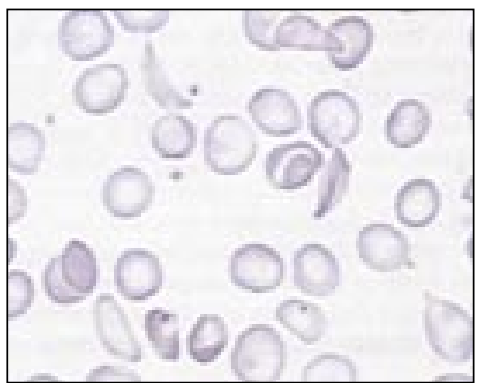

Figure 3.

Peripheral blood smear of the patient showing sickle cells, anisocytosis and evidence of hyposplenism (target cells, Howell-Jolly bodies).

\section{References}

1. Wolff MH, Sty JR. Orbital infarction in sickle cell disease. Pediatric Radiol.1985;15(1):50-2 Abstract

2. A D Naran and L Fontana. SCD with orbital infarction and epidural haematoma. Pediatric $R a-$ diol. 2001;31(4):257-9. Abstract

3. John P. Greer, John Foerster, John N. Lukens, George M. Rodgers, Frixos Paraskevas, and Ber- til Glader, editors. Wintrobe's Clinical Hematology. 11th edition. Philadelphia: Lippincott Williams \& Wilkins; 1999

4. AA Mallouh, M Young, J Hanmadan, and MM Salamah. Proptosis, skull infarction and retro-orbital and epidural haematoma in a child with SCD. Clin pediatric (phila). 1987;26(10):536-8.

5. RS Snell. Second Edition clinical anatomy for
Medical Students, p 698-699.

6. Graham R. Serjeant, Beryl E .Serjeant: Sickle cell disease, 3rd ed. New York: Oxford University Press; 2001.

7. Kikkawa DO; Pornpanich K; CruzRC; Levi L; Granet DB. Graded orbital decompression based on severity of proptosis. Ophthalmology. 2002;109(7):1219-2. Abstract 